\title{
Universal manufacturing: data, resiliency, and sustainability linkages
}

\author{
Andrew Kusiak $^{1}$ \\ Published online: 22 January 2022 \\ (c) The Author(s), under exclusive licence to Springer Science+Business Media, LLC, part of Springer Nature 2022
}

Digitization of manufacturing has coincided with a pressure to consider resiliency and sustainability in industry. Though the manufacturing sustainability and resiliency problems have been researched for some time, the natural disasters that have grown in intensity and scale as well as the COVID pandemic have intensified this pressure. The weak points of manufacturing resiliency (e.g., capacity shortages, disrupted supply chains) have been felt globally. The time scale for a more forceful reaction to manufacturing sustainability may be longer, however, the social pressure is growing and therefore a research attention is needed.

To accelerate progress in sustainability and resiliency, a support from optimization may be justified. Resiliency and sustainability could be bundled into a decision-making framework illustrated in Fig. 1.

Both, sustainability and resiliency may be reflected in the objective function and the solution space shaped by constraints.

Many sustainability solutions have cost implications and therefore a presence in the objective function is warranted. However, sustainability policies may largely impact constraints and thus shape the solution space.

Two primary strategies that apply to resiliency are the manufacturing scale and unification. The examples of manufacturing scale are a batch size and a production volume. Examples of unification in manufacturing include standardization and modularity. An increase in the scale or unification has a positive impact on manufacturing efficiency. Note that some degree of dependency may exist between standardization and manufacturing scale.

Besides enabling modeling and optimization of manufacturing enterprises, data allows visualization of manufacturing processes and services. Data collection in manufacturing comes at a cost, and therefore it needs to be justified. Deployment of the models discussed in the literature, from condition

Andrew Kusiak

andrew-kusiak@uiowa.edu

1 Department of Industrial and Systems Engineering, The University of Iowa, Iowa City, IA 52242-1527, USA monitoring to digital twins, offers benefits to industry. Perhaps the most significant benefit will come from sharing manufacturing models in the spirit of universal manufacturing introduced in Kusiak $(2021 \mathrm{a}, \mathrm{b})$ and illustrated in Fig. 2. At the core of universal manufacturing are enterprise models displayed in a cloud. An enterprise that needs to meet a sudden spike in the product demand can be formed from the component models. For example, model $\mathrm{M}$ in Fig. 2 is formed by merging two models, M4 and M2. Most merges in universal manufacturing are likely to be partial to meet the capacity, capability, quality, and other requirements.

While the concept of sharing manufacturing models in a cloud may sound alarming to some, a closer look at the issue may demonstrate that it could be more benign than the practice of revealing used in innovation (Kusiak, 2016). To measure customer reaction to the anticipated introduction of a new product, some companies reveal limited product information to potential customers ahead of the full-scale production. The risk of a gain from early customer feedback vs a potential loss to the competition is managed by the company revealing the initial product design.

In the manufacturing domain, tools and software are sold globally and therefore their functionality is known. Here, an analogy to the standard parts (e.g., screws) and modules (e.g., electric motors) can be drawn. They are used across many products manufactured by various companies.

In universal manufacturing, companies will control the information content of the cloud models. The models can be visualized at different levels with a varied access.

Industrial companies, including competing ones, merge. Some companies offer manufacturing service for products developed by competitors (Kusiak, 2019). Standards in the data domain (e.g., MTConnect) and process modeling (e.g., BPMN) have been developed (Kusiak, 2021b). Based on the analysis of industries, the elements of universal manufacturing can be spotted in many corporations. To accelerate the progress, a collaborative approach to the development and implementation of universal manufacturing is needed. 


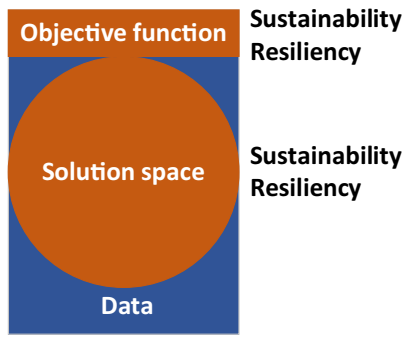

Fig. 1 Data enabled optimization of resiliency and sustainability

\section{References}

Kusiak, A. (2016). Put innovation science at the heart of discovery. Nature, 530(7590), 255.

Kusiak, A. (2019). Service manufacturing: Basic concepts and technologies. SME Journal of Manufacturing Systems, 52(Part A), 198-204.

Kusiak, A. (2021a). Universal manufacturing: Enablers, properties, and models. International Journal of Production Research. https://doi. org/10.1080/00207543.2021.1894370

Kusiak, A. (2021b). From digital to universal manufacturing. International Journal of Production Research. https://doi.org/10.1080/ 00207543.2021.1948137

Publisher's Note Springer Nature remains neutral with regard to jurisdictional claims in published maps and institutional affiliations.
Fig. 2 Example implementation of universal manufacturing

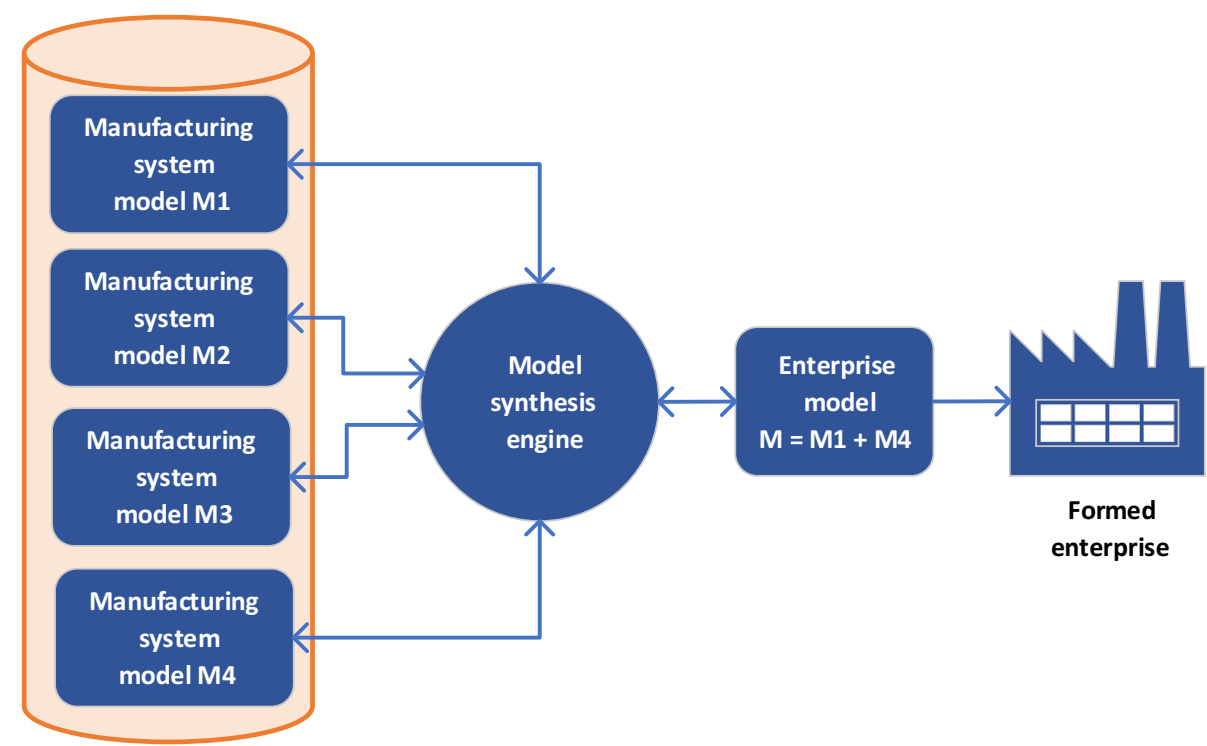

Universal manufacturing cloud 